\title{
A (I)LEGALIDADE DO INDEFERIMENTO PELA AUTARQUIA FEDERAL DO BENEFICIO RURAL EM RAZÃO DO LABOR URBANO DO CONJUGE
}

\author{
Nisslane Magalhães de Siqueira ${ }^{1}$
}

\begin{abstract}
RESUMO: O artigo propõe analisar a situação do trabalhador rural, que desenvolve seu labor em conjunto com o seu núcleo familiar, contudo face a escassez de recursos, um dos cônjuges desloca-se para centros urbanos aventurando melhores condições de vida, sem que isso implique na mudança dos demais membros da família, que continuam laborando no campo. $\mathrm{O}$ presente artigo propõe discutir a legalidade do indeferimento administrativo pela autarquia federal, Instituto Nacional de Seguro Social, a partir da edição da súmula da Turma Nacional de Jurisprudência, por meio da investigação teórica, em especial as de face conceitual, normativa e zetética empírica aplicada, para a concessão do beneficio rural a cônjuge, sob alegação de comprovação de labor urbano do cônjuge com base na atividade urbana.
\end{abstract}

Palavras-Chaves: Atividade Urbana; Atividade Rural; Núcleo Familiar; Comprovação Laboral; Casamento.

\section{UNLAWFUNESS OF INDEFETOMENTO AUTARQUIA FEDERAL BENEFIT OF THE HUSBAND'S WORK}

\begin{abstract}
This paper analyses agriculture worker who develop its job connected to his familiar core, however, inside a context of lack of resources, one of the conjugated drives by himself to the urban centers in order to try better life conditions, while the rest of the family stay working in the country. The text discusses the value of the state prohibition by the Instituto Nacional de Seguro Social, according the rule of National Group of Precedents, through theory analysis, specially the conceptual side and applied empirical normative in order to grant the right to the conjugated, once that it was considered proved the country activity to get right.
\end{abstract}

Keywords: Urban Labor; Agriculture Labor, Familiar Core, Labor Proof, Marriage.

\footnotetext{
${ }^{1}$ A autora é mestranda em Direitos Sociais e Relações Trabalhistas pela UDF, possui pós graduação lato sensu em Direito do Trabalho e Processo do Trabalho, e em Direito Tributario, ambos pelo Instituto de Ensino Superior Unyahna, e em Docência Universitaria pela Universidade Estadual da Bahia. É graduada em direito pelo Instituto de Ensino Superior Unyahna. Atualmente coordena o curso de Direito da Faculdade Dom Pedro II, unidade de Barreiras-BA. CV: http://lattes.cnpq.br/1789761110150920
} 


\section{1-INTRODUÇÃO}

A Seguridade Social esta alicerçada na Constituição Federal, sendo importante que se enfatize que a Carta Magna, a contemplou como parte do núcleo dos direitos humanos fundamentais, até então não apresentado nas constituições brasileiras anteriores com tamanha extensão, criando subsistemas ${ }^{2}$ para garantir a saúde, assistência e previdência. (CRUZ, 2015)

Os direitos humanos são construídos pela sociedade, não sendo estes preexistentes, havendo uma demonstração clara de preocupação com a redução da desigualdade ${ }^{3}$. (IBRAHIM, 2012, p. 77) Na perspectiva das dimensões de direitos humanos é denominada de $3^{\circ}$ geração dos Direitos Fundamentais, como instrumento nesse emaranhado complexo recepcionado no cenário da Constituição Federal, tendo assim maior possibilidade de efetivação dos direitos sociais.

Frisa- se a esse contexto a preocupação imbuída na previdência de noção teleológica de solidariedade, amparando e sustentando o sistema previdenciário vigente.

Nesse contexto, o trabalhador rural assumiu um novo status dentro da previdência social, principalmente com a releitura do princípio da igualdade, sendo-o equiparado na qualidade de trabalhador ao urbano. Frisa-se que essa igualdade antes formal, agora consegue materializar-se como veremos a frente.

Estariam a partir dai, conceituados, e com tratamento diferenciado de aposentadoria, os "rurais", no que tange ao tempo, condições, carência e intencionalidade na concessão do benefício, requisitos que levam em consideração as primícias das circunstâncias da efetiva atividade do segurado.

É de se ponderar, que as condições que norteiam o beneficio, são concedidos em razão da situação sui generis do trabalhador rural, que a priori passou o Estado a ponderar sua importância na economia, de onde provem todo alimento que chega a mesa, a instabilidade de suas atividades, das condições de vulnerabilidade em que estão sujeitos em razão da própria atividade face as condições principalmente naturais e/ou ambientais, e o interesse social de que se mantenham no campo.

Neste contexto, a igualdade material é promovida, a partir de parâmetros diferenciados de outros institutos, que carece de estudo acerca do objeto do trabalho, que fragiliza aquele que

\footnotetext{
${ }^{2}$ Para Celio Rodrigues Cruz, o artigo 194 da Constituição Federal de 1988, possui um sistema integrado de politicas.

${ }^{3} \mathrm{O}$ autor destaca a Seguridade Social como um Direito inerente ao Humano, concluindo que os direitos humanos são indivisíveis, sendo indevida qualquer subdivisão.
} 
laborou em regime que economia familiar, qual seja: a (i)legalidade no indeferimento da aposentadoria rural pela autarquia federal à trabalhadora rural, em que o cônjuge contenha labor urbano.

A inovação jurídica reside na edição da sumula 41 da Turma Nacional de Uniformização, a saber: "A circunstância de um dos integrantes do núcleo familiar desempenhar atividade urbana não implica, por si só, a descaracterização do trabalhador rural como segurado especial, condição que deve ser analisada no caso concreto. "4. Exemplo de concretude dos direitos sociais, editados na Constituição Federal. Neste caso para a concessão do beneficio deve-se levar em consideração a instabilidade financeira decorrente da sacionalidade da atividade, além do reconhecimento pormenorizado da situação dos beneficiários, como do seu núcleo familiar rural.

A discussão justifica-se pela importância social do tema, com a finalidade de se analisar a sua completude ao sistema constitucional previdenciário, com amparo aos direitos humanos fundamentais, utilizando-se metodologicamente de investigação teórica, em especial as de face conceitual, normativa e zetética empírica aplicada

Para fins didáticos o texto será dividido em três capítulos, sendo que um tratara da previdência como direito fundamental na Constituição Federal com um olhar para a aposentadoria rural, no segundo momento será tratado as considerações acerca da aposentadoria Rural, analisando a partir da lei infraconstitucional no8212/91, e a lei nº213/91, as características e requisitos. No terceiro capitulo será tratado a problemática a partir da analise da (i)legalidade do indeferimento da aposentadoria rural com base no labor urbano do cônjuge.

Nesse contexto será exposto os motivos ensejadores das razões do Instituto Nacional do Seguro Social, em contraponto a Sumula 41 da Turma Nacional de Unificação dos Juizados Especiais Federais.

Não é o objetivo do estudo buscar uma resposta para a questão mas tão somente, analisar criticamente as circunstancias que envolvem a lide.

\footnotetext{
${ }^{4}$ As premisas trazidas a baila pela Turma Nacional de Uniforização de Jurisprudência, busca corrigir distorções ao sistema de concessão de benefício, atribuindo uma analise pontual nos casos concretos, assegurando o cumprimento dos direitos sociais
} 


\section{2- A PREVIDENCIA COMO DIREITO FUNDAMENTAL NA CONSTITUIÇÃO}

\section{FEDERAL 1988}

A Carta Magna de 1988 trouxe um novo status a dimensão da seguridade, coadunando com a nova teleologia democrática social, sendo criado para a sua efetivação a autarquia federal com caráter centralizador, o INSS-Instituto Nacional do Seguro Social, propiciando uma ampliação de coberturas e sendo uma das mais relevantes inovações da Constituição Federal. ${ }^{5}($ DELGADO, 2010)

Os princípios constitucionais previdenciários estariam voltados para a solidariedade, com posição nuclear, sendo esse preceito o sustentáculo de toda a estrutura. A ausência deste princípio tornaria impossível a manutenção da estrutura de proteção social ${ }^{6}$, que temos atualmente. (MARTINEZ, 2014).

Além do exposto, outros pontos devem ser levados a analise, para instrumentalização do direito, a saber, a universalidade da cobertura e do atendimento; uniformidade e equivalência de prestações entre população urbana e rural, seletividade e distributividade na prestação dos benefícios e serviços; irredutibilidade do valor dos benefícios; eqüidade na forma de participação no custeio; diversidade de base e de financiamento, caratér democratico e descentralizado da Administração, prexistência do custeio em relação ao beneficio ou serviçoregra de contrapartida. ${ }^{7}$ (IBRAIM, 2014)

Além desses citados acima, para o estudo em apresso, é necessário analisar o princípio da igualdade como instrumento da dignidade da pessoa humana, que desponta como pedra angular para a proposta do estudo, uma vez que tão ou mais importante que a igualdade formal que não desapareceu da constituição, emerge na noção humanista e social a igualdade material.

Em uma primeira analise, os trabalhadores urbanos e rurais foram equiparados, conforme artigo $7^{80}$ da Constituição Federal, assim os desprestigiados trabalhadores rurais, passariam a estar em outro patamar, nesse aspecto Fabio Zambite Ibrahim, (2014, p.21)

\footnotetext{
${ }^{5}$ Destaca-se a importancia da previdência, como uma politica publica de concretude dos direitos sociais, além do status da sua relevância na Constituição Federal.

${ }^{6} \mathrm{O}$ autor elucida a solidariedade como principal princípio previdenciário, atribuindo a este o significado, a origem, seus limites, tipos e sua aplicação no ordenamento jurídico brasileiro, sendo o sustentáculo para toda estrutura de previdência.

${ }^{7}$ IBRAIM, Fabio Zambitte. Na obra Resumo de Direito Previdenciario, aborda os principios expostos acima, demonstrando a sua indicação no documento constitucional. Relacionando a constitucionalidade do direito previdenciário.

${ }^{8}$ Constituição Federal 88 Art. $7^{\circ}$ São direitos dos trabalhadores urbanos e rurais, além de outros que visem à melhoria de sua condição social.
} 
“Apesar de área rural ser extremamente deficitária, a igualdade de tratamento justifica, já que todos são trabalhadores. Se as contribuições rurais não atingem patamar adequado, isto não é culpa do trabalhador. Ademais cabe aqui o principio da solidariedade- os trabalhadores urbanos auxiliam nos benefícios no custeio dos benefícios rurais" 9

Nesse diapasão, o artigo $194^{10}$ da Constituição Federal, assegura a estrutura da previdência calcada no tripé previdência, assistência e saúde, com a União assumindo a responsabilidade desse complexo sistema previdenciário, devendo estar apto a analisar as variações que o instituto preveria, em razão de questões econômicas, sócias, a exemplo.

Cumprindo a proposta que o direito pretende atuar, leciona Mauricio Godinho (2017):

\begin{abstract}
"Em relação a dinâmica social, o direito tende a atuar, essencialmente, de duas maneiras (que podem obviamente combinar-se): antecipa formulas de organização e conduta para serem seguidas na comunidade ou absorve praticas organizacionais e de conduta já existentes na convivência social, adequando-se as regras e princípios fundamentais do sistema jurídico circundante" ${ }^{11}$.
\end{abstract}

O tema toma urna proporção mais relevante quando analisamos as atribuições ao atendimento da previdência social. Independe da concretude de um direito de segunda dimensão $^{12}$, pois a sua implementação e efetivação, pode variar em razão das circunstancias que envolvem o tema, tais como a situação econômica e social do país.

Sua previsão constitucional vai além de definir como um direito fundamental, mas devese fazer o seu planejamento orçamentário para a concretude e aplicabilidade de politicas públicas para faze-las, sendo uma necessidade de todos os Estados desenvolvidos.

Para Fabio Zambitte (2010)

\footnotetext{
9 Obra ja citada de Ibrahim, pg. 23.

${ }^{10}$ Constituição Federal Art. 194 . A seguridade social compreende um conjunto integrado de ações de iniciativa dos Poderes Públicos e da sociedade, destinadas a assegurar os direitos relativos à saúde, à previdência e à assistência social.

${ }^{11}$ Mauricio Godinho Delgado na obra Principios Constitucionais do Trabalho e Principios do Direito Individual e Coletivo do Trabalho, afirma que o direito possui a função de regulamentar as mudanças sociais, com possibilidade inclusive de amparar institutos novos.

12 Conforme ja trazido acima, o Autor Fabio Zambitte, faz duras criticas a tentativa de classificar a previdencia social, em uma dimensão dentro dos direitos humanos.
} 
“Admitir a previdência social como direito fundamental é uma necessidade. Muitos criticam o enquadramento, mas poucos conseguiriam viver em uma sociedade sem essa. O seguro social é meio necessário e eficaz de garantia da vida digna, firmando sua posição em todas as sociedades desenvolvidas". ${ }^{13}$

Sem esquecer a atribuição do Estado em sua implementação, caberá a União a responsabilidade e a verificação da possibilidade de estar presente na previsão orçamentaria para que tal fato aconteça, uma vez que as necessidades de demandas das macelas sociais, não são acompanhadas de recursos para resolve-los.

Nesse diapasão, o professor Celio Rodrigues Cruz (2015), traz o seguinte desfecho:

\begin{abstract}
“A União tem o dever de assegurar um regime geral de previdência social, de caráter contributivo e de filiação obrigatória, observados critérios que preservem o equilíbrio financeiro e atuarial, com a finalidade de oferecer prestações que acobertem os riscos sociais qualificados pela Lei Maior. “14
\end{abstract}

Outro ponto que merece destaque diz respeito ao artigo 201, que traria uma significativa alteração na renda dos trabalhadores rurais, prevendo que não mais poderiam ser inferiores a um salario mínimo, os benefícios do salário de contribuição, ou o rendimento do trabalho do segurado. Nota-se com isso a preocupação em combater as desigualdades sociais existentes. Entretanto, os segurados que recebiam na época valor inferior ao salario mínimo, tiveram que demandar judicialmente a alteração, não sendo essa reconhecida de imediato para casos pretéritos.

Nesse contexto, com efeito, a situação dos trabalhadores rurais ${ }^{15}$, a partir da Constituição Federal de 1988, é bem diferente do que antes: os direitos dos empregados rurais foram igualados aos dos empregados urbanos; houve redução de idade para aposentadoria; os

\footnotetext{
${ }^{13}$ Para o autor é inaceitavel que se fale liberdade do homem, quando este encotra-se preso a macelas e fragilidades sociais, assi esses intrumentos possuem o condão da dignidade da pessoa humana

${ }^{14}$ Obra já citada, Cruz, Celio Rodrigues

${ }^{15}$ Roberto Élito dos Reis na o artigo Trabalhador Rural e a Previdência Social - Evolução Histórica e Aspectos Controvertidos, apresenta a evolução da situação do trabalhador rural e consequentemente o impacto social que desenvolveu a partir da Constituição Federal, demeonstrando a centralidade da dignidade da pessoa humana.
} 
respectivos cônjuges passaram a ter direito à aposentadoria e nenhum benefício seria inferior ao salário mínimo. (GUIMARÃES, 2008)

\section{3- CONSIDERAÇÕES DO BENEFICIO RURAL}

O Brasil possui sua economia calcada na produção rural, sendo o setor primário, o de maior destaque no índice econômico. Contudo a agricultura não se limita aos grandes números ligados a exportação, parte da comida que chega as mesas são provenientes da agricultura familiar. Essa que na maioria das vezes, é promovida em pequenas faixas de terra, por pequenos produtores em seu núcleo familiar.

No entanto, os trabalhadores rurais, ficaram relegados, sendo tratados de forma diferente dos trabalhadores urbanos, o que impulsionava o êxodo rural, migrando-os para os grandes centros. É claro que este não é o único fator que promoveu o êxodo rural no país, mas a falta de uma promoção ou politica social para o homem do campo.

$\mathrm{Na}$ Previdência não foi diferente. Com o advento da Lei Complementar $\mathrm{n}^{\circ} 11$ de 25 de maio de 1971,foi criado o Fundo de Assistência e Previdência do Trabalhador Rural FUNRURAL, que atenderia aos trabalhadores rurais com benefícios de aposentadoria e pensões. Destaca-se que esse fundo inicialmente não previa a teleologia do art. 201 da Constituição Federal de 1988, que imputava pagamento inferior ao salario mínimo, e colocava condições diferentes para a concessão dos benefícios, distinguindo homens e mulheres.

Posterior com o advento da Constituição Federal de 1988, e a ampliação dos direitos sociais, os segurados rurais passaram a dispor de um tratamente deferenciado, elevando o status social para segurados com condições especiais (ARAUJO, 2014)

A sua efetividade, no entanto, só veio ocorrer com o advento das Leis Infraconstitucionais $\mathrm{n}^{\circ} 8.212 / 91$, Lei ${ }^{\circ} 8.213 / 91$, classificando os trabalhadores rurais em três categorias, quais sejam: o empregado rural; o trabalhador contribuinte individual e o segurado especial ${ }^{16}$, objeto do estudo.

$\mathrm{O}$ art. 11, VII $^{17}$, da lei 8213/91, atribui a condição e as circunstâncias para serem segurados especiais, incluindo no seu rol a condição do conjuge. Entretando essa interpretação

\footnotetext{
${ }^{16}$ Obra já citada, Roberto Élito dos Reis Guimarães

${ }^{17}$ Lei 8213/91 Art.11.São segurados obrigatórios da Previdência Social as seguintes pessoas físicas: [...] VII como segurado especial: o produtor, o parceiro, o meeiro e o arrendatário rurais, o pescador artesanal e o assemelhado, que exerçam essas atividades individualmente ou em regime de economia familiar, ainda que com auxílio eventual de terceiros, bem como seus respectivos cônjuges ou companheiros e filhos maiores de quatorze anos ou a eles equiparados, desde que trabalhem, comprovadamente, com o grupo familiar respectivo. § 6o Para
} 
sempre parte da premissa que o homem mantem-se na postura do arrimo familiar, ignorando a possibilidade da mulher em determinados momentos conduzir a subsistência da familia, mesmo estando casada.

A priori, para melhor compreensão da matéria, é necessário definirmos o que é o regime de economia familiar, que esta conceituado na lei 8213/91, no seu art.11, V, $\S 1^{\circ}$, tendo sido alterado com o advento da lei11.718/2008.

\footnotetext{
"Entende-se como regime de economia familiar a atividade em que o trabalho dos membros da família é indispensável à própria subsistência e ao desenvolvimento socioeconômico do núcleo familiar e é exercido em condições de mútua dependência e colaboração, sem a utilização de empregados permanentes."
}

Pode-se de compreender que dentro outras coisas, a legislação tentou promover aos que laboram na zona rural, dentro da concepção gênero, ao segurado especial, condições mínimas previdenciárias para a sua manutenção no campo, estendendo-se para todo o núcleo familiar. A inteligência do artigo $11, \mathrm{~V}, \S 6^{\circ}$, requer que de forma ativa os membros laborem no campo para também serem considerados segurados especiais.

Para a concessão do beneficio a legislação trouxe um rol de documentos que comprovem a atividade rural, sendo analisados pela autarquia de forma taxativa, o que tem atribuído um enorme número de ações judiciais em razão do indeferimento na via administrativa.

Tal elevado índice de judicialização, foi trazido como argumento da PEC na "REFORMA DA PREVIDENCIA" (atualmente sem força politica para sua aprovação), que prevê alterações significativas em tal instituto. Em 2015 cerca de 30,5\% das aposentadorias rurais foram concedidas garantidas por decisões judiciais, segundo dados do IPEA ${ }^{18}$. Uma pesquisa mais apurada pelo Instituto revela que essas demandas judiciais, devem-se as variações de discricionariedade contidas pela autarquia federal INSS, uma vez que

serem considerados segurados especiais, o cônjuge ou companheiro e os filhos maiores de 16 (dezesseis) anos ou os a estes equiparados deverão ter participação ativa nas atividades rurais do grupo familiar. .Nota-se que a lei $8218 / 2008$, traz inumeras mudanças, inclusive no tangente a contratação de funcionarios.

18 ARBEX, Alexandre, e GALIZA, Marcelo, Reforma Da Previdência, Agricultura Familiar e os Riscos de Desproteção Social Repositorio do Instituto de Pesquisa Economica Aplicada. Disponivel:http://repositorio.ipea.gov.br/bitstream/11058/7818/1/bmt_62_reforma_previd\%C3\%AAn cia.pdf. Os dados demonstram a necessidade de uma revisão pela autarquia federal e como esse discurso vem sendo usando a favor da reforma da previdencia. 
judicialmente, outras provas são demonstradas que corroboram com a situação fática comprovada de segurado especial.

A discricionariedade da autarquia, associado a não utilização de todos os meios de prova para a comprovação da qualidade de segurado tem sido os fatores preponderantes para o indeferimento administrativo. No que diz respeito a concessão desses benefícios na seara judicial, no tocante as provas, tem-se como base que o juiz, no processo de conhecimento busca a reconstrução dos fatos, já que a sua função essencial nos autos é a busca da verdade. ${ }^{19}$ Tamanha é a importância da verdade para dirimir lides.

Essa preocupação, pela busca da verdade, já foi externada dentro da Turma Nacional de Uniformização dos Juizados Federais, sendo essa matéria solidificada através da sumula 41, a saber:

Súmula 41 TNU: A circunstância de um dos integrantes do núcleo familiar desempenhar atividade urbana não implica, por si só, a descaracterização do trabalhador rural como segurado especial, condição que deve ser analisada no caso concreto. $^{20}$

Assim sendo, o que ensejaria o indeferimento com base na atividade urbana do conjuge?

A atividade rural, por vezes reveste de instabilidades diante dos fatos ambientais, além das sacionalidades da própria atividade, ou seja, demanda de eventos não previsíveis. Ademais a agricultura familiar conforme conceitua a lei, geralmente aufere-se "pouca monta", até mesmo em face da pequena area produzida.

Neste contexto é possivel que em determinados momentos impere a necessidade que um dos conjuges, em que pese para o estudo em apresso conjuge varão, de procurar um labor urbano, sem contudo que o outro se afaste do ambiente rural. Nesse diapassão continua desenvolvendo as atividades para a manuntenção da agricultura familiar.

\footnotetext{
${ }^{19}$ MARINONI, Luiz Guilherme, e ARENHART, Sergio Cruz. Curso de Processo Civil, vol.2 Processo de Conhecimento, $12^{\circ}$ ed. São Paulo Revista dos Tribunais, 2014. Pg.247-265. O autor traz no subtitulo $A$ Verdade e a Função da Prova, onde demonstra a responsabilidade do de se buscar a verdade atraves da prova.

${ }^{20}$ Sumula da Turma Nacional de Uniformização dos Juizados Especiais Federais. "Compete à Turma Nacional processar e julgar o incidente de uniformização de interpretação de lei federal em questões de direito material fundado em divergência entre decisões de turmas recursais de diferentes regiões ou em face de decisão de uma turma recursal proferida em contrariedade à súmula ou jurisprudência dominante do Superior Tribunal de Justiça." Acesso: http://www.cjf.jus.br/cjf/tnu/competencia, acesso em 28/01/2018.
} 
Assim, os outros demais membros do núcleo familiar, a saber a conjuge varoa, permanece com as atividades na area rural, não cessando sua qualidade de segurada rural, para todos os efeitos.

Para um entendimento sistematico do texto, é necessário analisar dentro do direito de família, o conceito de casamento disposto no artigo 1.511 do Código Civil. "O casamento estabelece comunhão plena de vida, com base na igualdade de direitos e deveres dos cônjuges”, conjugado com o artigo 1569, do mesmo Código “O domicílio do casal será escolhido por ambos os cônjuges, mas um e outro podem ausentar-se do domicílio conjugal para atender a encargos públicos, ao exercício de sua profissão, ou a interesses particulares relevantes". ${ }^{21}$

Nesse contexto, o direito patrio vem elastecendo o conceito de familia, tendo na jurisprudência majoritaria o entendido conceitual de estrutura familiar inovado, ou ajustado com as novas relações socias. Dentro desse entendimento, o casamento ou união estavel, não cessaria com a ausência de um dos conjuges do lar, condição esse prevista na legislação vigente, o que coaduna com o entendimento da súmula.

\section{4-A (I)LEGALIDADE DO INDEFERIMENTO DO BENEFICIO COM BASE NO LABOR DO CONJUGE}

A Autarquia Previdenciária, administrativamente vem desqualificando a condição da situação de segurada especial rural, em razão do labor urbano do conjuge, indeferindo o pedido de segurada especial.

O deferimento do pedido se pauta na manutenção da qualidade de segurada, mais conjunção do fator idade. Para a comprovação da qualidade de segurada é requerido um rol de documentos que comprovem a situação de beneficiaria.

Entretando esse rol que deveria ser exemplificativo, acaba por ser utilizado com taxativo, limitando-se a utilização de outros meios de produção de provas, nesta feita a apresentação do labor do conjuge em atividade urbana, impossibilita a concessão do beneficio, sobre a alegação de dependência econômica presumida.

\footnotetext{
${ }^{21}$ Aduz o artigo 1.566 do Código Civil. "São deveres de ambos os cônjuges: (...)II - vida em comum, no domicílio conjugal". O artigo 1569, preve a possibilidade do afastamento de um dos conjuges do lar em razão do labor, e sem isso abalar a estrutura da concepção de casamento.
} 
Tendo o orgão em questão, informações privilegiadas a respeito da condição do conjuge, diante dos instrumentos da armazenamento de informações, o pedido do requerente é indeferido, desconsiderando todas as demais provas no processo administrativo.

A economia familiar clássica deixa claro que as atividades desenvolvidas no seio rural, são atribuidas a todos os membros da familia, assim nessa engrenagem todos desenvolvem papéis ativos. Quando um dos membros, temporariamente cessa a atividade, os demais membros continuam como segurados.

Por vezes indeferimento do pleito, alega-se a dependência econômica presumida da conjuge, descartando a possibilidade que durante o labor urbano do companheiro essa tenha permenecido no ambiente rural, e desenvolvendo agricultura de subsistência, desacreditando na emancipação feminina, ou ainda a concepção classica do casamento, excluindo a possibilidade de um dos conjuges por motivo de trabalho, habitarem em residências diferentes, conforme prevê o artigo 1569 do Codigo Civil.

Pauta-se a referida autarquia, que existe o cumprimento da coabitação entre os conjuges, como requisito ou condição para a manutenção do casamento, entendimento superado pela doutrina e pelos tribunais brasileiros já há muito tempo.

No tocante ao tema o doutrinador Paulo Lobo (2005) leciona:

\footnotetext{
“A permissão de ausentar-se não significa que possa cada cônjuge ter domicílio próprio. No entanto, com a emancipação feminina e a inserção crescente das mulheres no mercado de trabalho, inclusive em cidades distintas de seus maridos, o dever de coabitação mostra-se ultrapassado. Por outro ângulo, o princípio da liberdade familiar, de fundo constitucional, afeiçoa-se à escolha dos cônjuges em viverem em domicílios separados por conveniência pessoal."
}

Atente-se que os demais ramos do direito já consagraram o entendimento acerca da convivência para a manutenção da condição do casamento, tendo a inteligência da sumula 41 da TNU, possibilitado uma analise mais apurada dos fatos, excluindo um dos membros sem desclassificar os demais integrantes, atendendo a teleologia juridica constitucional previdenciária.

A discursão da materia se deu inclusive, em uma ação em que a esposa trabalhava como professora no periodo em que o requerente estaria na qualidade de segurado especial, tendo seu pedido negado no juiz singular e e pela $2^{\circ}$ Turma Recursal do Paraná, nestes termos a TNU em 
2010, levando em consideração o que reza o artigo 11, VII, da lei 8213/91, que o segurado pode exercer suas atividades individualmente ou em regime de economia familiar, ainda que com auxilio eventual de terceiros, decidiu por deferir o pedido.

É portanto, necessário a analise de provas que evidenciem o desenvolvimento da atividade, vez que essa se dara por meio de todas as provas admitidas em direito, para tanto.

Não se pode excluir dessa analise, inovação trazida no direito de familia, das atribuições pertinentes ao casamento, já aceito em outros ramos de direito, não excluindo a possibilidade do dialógo entre as fontes.

Em que pese, os argumentos trazidos no estudo, não se requer o deferimento dos pedidos sem cuidado, pelo contrário, a analise demonstra que a autarquia federal, deveria analisar os pedidos admitindo possibilidade extensiva de provas, em busca da verdade real, evitando-se assim que os indeferimentos administrativos, fossem deferidos judicialmente.

\section{5- CONCLUSÃO}

Com o advento da Constituição Federal, a previdência social passou a compor o rol de direitos fundamentais, até então relegado nas constituições anteriores. Nesse diapassão os trabalhadores rurais tiveram um novo status nesse cenário social, sendo equiparados aos urbanos.

A Previdência passaria a ser norteada pelo princípio da solidariedade, figurando então nesse rol os segurados especiais rurais, com o intuito de combater desigualdades sociais impostas, além de reconhecer a importância da permanência do labor do campo, através da agricultura familiar.

Percebe-se a preocupação do legislador, em conceituar a agricultura familiar, e colocar as modalidades ali inseridas, possibilitando que o labor rural aconteça tanto de forma individual, como em regime de econômia familiar, possibilitando que todos os membros da família possam compor esse núcleo.

Percebe-se contudo, através dos dados do IPEA, inclusive argumento trazido para justificar a reforma da previdência, no que concerne a alteração da condição de segurados especiais rurais, um crescente número de beneficios concedidos judicialmente. Some-se a tudo isso, a atuação da autarquia federal que traz a limitações impostas para apresentação das provas administrativamente, nem a discricionariedade do referido orgão. 
Então o que se percebe é a busca pela verdade, através das provas no cenário judicial, analisando cada caso, conforme a teleologia da súmula 41 da TNU. O discurso da autarquia, apenas limita-se a dependência econômica presumida, e aos laços de convivência/ moradia em comum.

Nestes termos, se para a analise do beneficio especial rural pleiteado pelo homem em que a conjuge desenvolveu labor urbano torna-se extremamente dificil administrativamente, para a mulher em que o homem desenvolveu labor urbano, é quase que cruel, pois para o indeferimento utiliza-se como subterfúgio ao labor urbano do seu cônjuge, sem levar em consideração os requisitos gerais para a concessão do beneficio.

Ignora-se com a falta de analise, a sacionalidade atribuida ao labor rural per si, em que determinados momentos o conjuge varão procura labor urbano, enquanto a varoa continua desenvolvendo as atividades rotineiras do campo, sozinha ou com a ajuda de outros membros da família.

A solução não é o deferimento dos beneficios, mas analisar todas as provas admitidas em direito, o que inviabilizaria inclusive inúmeros pedidos revertidos judicialmente, diminuindo substancialmente a médio prazo demandas judiciais. Outro ponto que merece destaque como complemento da ideia anterior, é a aplicação da inteligente da súmula, requerendo uma analise do caso concreto.

Ademais, a função da previdencia rural vai além da concessão de beneficios rurais, segundo o IPEA a taxa de pobreza da população rural caiu de 73,8\%, em 2005, para 49,5\%, em 2014, e isso não pode ser desconsiderado.

Neste contexto, a decisão emitida pela Autarquia Federal que não leva em consideração todos os pontos tratados acima, além de remontar a ilegalidade ao segurando, pois tem seu beneficio indeferido indevidamente, ainda traz prejuizos a administração pública e a economia como um todo, uma vez que terá que implementar e beneficio, além de corrigi-los, após a apreciação judicial.

\section{REFERÊNCIA}

ARAÚJO, Carloman Junior Conceição; ALVES. O segurado especial e a comprovação da atividade rural nos termos da Lei 8213/91. Boletim Jurídico, Uberaba/MG, a. 13, n $^{\circ} 1228$. Disponível em: <https://www.boletimjuridico.com.br/doutrina/texto.asp?id=3941> Acesso em: 22 de fevereiro de 2018

ARBEX, Alexandre, e GALIZA, Marcelo, Reforma Da Previdência, Agricultura Familiar e os Riscos de Desproteção Social Repositorio do Instituto de Pesquisa Economica Aplicada. 
Disponivel:http://repositorio.ipea.gov.br/bitstream/11058/7818/1/bmt_62_reforma_previd\%C 3\%AAncia.pdf

BRASIL. Constituição da Republica Federativa do Brasil, 1988. Disponivel em: http://www.planalto.gov.br/ccivil 03/constituicao/constituicaocompilado.htm. Acesso $21 \mathrm{de}$ janeiro de 2018.

Lei 8.212 de 24 de julho de 1991. Dispõe sobre a organização da Seguridade Social, institui Plano de Custeio, e dá outras providências. Brasília, DF, 24 jul. 1991. Disponível em: <http://www.planalto.gov.br/ccivil_03/leis/L8212cons.htm>. Acesso em: 20 de fevereiro de 2018.

Lei $\mathbf{n}^{0}$ 8.213, de 24 de julho de 1991.Dispõe sobre os Planos de Benefícios da Previdência Social e dá outras providências. Brasília, DF, 24 jul. 1991. Disponível em: < http://www.planalto.gov.br/ccivil_03/leis/18213cons.htm>. Acesso em 20 de fevereiro de 2018

Decreto no 3.048, de 6 de maio de 1999. Aprova o Regulamento da Previdência Social, e dá outras providências. Brasília, DF, 6 maio 1999. Disponível em: < http://www.planalto.gov.br/ccivil_03/decreto/D3048.htm>. Acesso em: 20 de janeiro de 2018.

CRUZ, Celio Rodrigues A Seguridade social na Constituição Federal de 1988. Disponivel: https://professorceliocruz.jusbrasil.com.br/artigos/220032431/a-seguridade-social-naconstituicao-federal-de-1988. Acesso em 22/12/2017

DELGADO, Guilherme e outros. Seguridade Social: Redefinindo o alcance da cidadania. Relatório da Seguridade Social. Capitulo 1. Brasília. IPEA, 2010

DELGADO, Mauricio Godinho. Proncipios Constitucionais do Trabalho e Principios do Direito Individual e Coletivo do Trabalho, $5^{\circ}$ ed., São Paulo: Ltr,2017.

GUIMARÃES, Roberto Élito dos Reis O Trabalhador Rural e a Previdência Social - Evolução Histórica Aspectos Controvertidos. Disponivel em: www.agu.gov.br/page/download/index/id/580103.

IBRAHIM, Fabio Zambitte, A Previdência Social como Direito Fundamental, Editora Impetus. Disponivel em: https://www.impetus.com.br/artigo/.../a-previdencia-social-como-direitofundamental

IBRAHIM, Fabio Zambitte, Curso de Direito Previdenciário, $17^{\circ}$ ed. Rio de Janeiro, Ed. Impetus, 2012

IBRAIM, Fabio Zambitte. RESUMO DE Direito Previdenciario, Ed. Impetus, $13^{\circ}$ edição, 2014. Pag 21-27

LOBO, Paulo, As vicissitudes da igualdade e dos deveres conjugais no direito brasileiro, disponivel: $\quad$ https://jus.com.br/artigos/6929/as-vicissitudes-da-igualdade-e-dos-deveresconjugais-no-direito-brasileiro

MARTINEZ, Wladimir Novaes, Curso de Direito Previdenciário, , 6º ed., São Paulo, LTr, 2014 RUBIN, Fernando. Introdução Geral à Previdência Social, Dos conceitos teóricos, institutos fundamentais e rede de benefícios do regime previdenciário brasileiro. São Paulo, LTr, 2016, 20 de janeiro de 2018.

TNU - Turma Nacional de Uniformização. Súmula $\mathbf{n}^{\mathbf{0}}$ 41. Disponível em: <http://www.dataprev.gov.br/servicos/cadint/DefinicoesBSegurado.htm>. 